\title{
OS IMPACTOS DO MEDO DO CRIME SOBRE O CONSUMO DE ATIVIDADES DE LAZER NO BRASIL
}

\author{
CRISTIANO AGUIAR DE OLIVEIRA \\ Professor do Provgrama de Pós-Graduação em Economia Aplicada da Universidade Federal do Rio Grande (PPGE/Furg) \\ País: Brasil Estado: Rio Grande do Sul Cidade: Rio Grande \\ Email de contato: cristiano.oliveira@furg.br ORCID: https://orcid.org/0000-0003-4933-6616
}

\section{DANIELE MENDES SILVA}

Mestre em Economia Aplicada pelo Programa de Pós-Graduação em Economia Aplicada da Universidade Federal do Rio Grande - PPGE/FURG. Bacharela em Ciências Econômicas pela Universidade Federal de Ouro Preto (2016). Tem interesse em temas que envolvem análise de políticas públicas, métodos quantitativos aplicados à economia, econometria , estatística espacial, desenvolvimento regional, economia social, mercado de capitais, área financeira e qualidade.

País: Brasil Estado: Minas Gerais Cidade: João Monlevade

Email de contato: silvadanimendes@gmail.com ORCID: https://orcid.org/0000-0002-3630-3922

\section{Contribuição de cada autor:}

Daniele Mendes realizou o levantamento de dados, as estimações e sua análise e contribuiu para a elaboração do texto do artigo. Cristiano Aguiar de Oliveira orientou a pesquisa, revisou as estimações e sua análise e contribuiu para a elaboração do texto do artigo.

\section{RESUMO}

Este estudo tem o objetivo de avaliar como o medo do crime afeta o consumo de atividades de lazer dos indivíduos, tais como ir a cinemas, shoppings, parques, eventos esportivos, feiras, bares, restaurantes e shows. Para este fim, utiliza os dados da Pesquisa Nacional de Vitimização do ano de 2012 para estimar um Probit bivariado recursivo, um modelo capaz de lidar com potenciais problemas de endogeneidade. Os resultados indicam que o medo do crime reduz a probabilidade do consumo de lazer da maioria das atividades investigadas, com destaque para eventos esportivos, com redução estimada em 13,2\%, contudo, foi observado um aumento no consumo de atividades que oferecem mais segurança para os consumidores, tais como feiras e shoppings centers, com aumentos estimados de $6 \%$ e 7,2\%, respectivamente. O estudo conclui que a criminalidade traz perdas de bem-estar que vão além das perdas econômicas costumeiramente contabilizadas em estudos de custos do crime, pois não se pode ignorar que o medo do crime é capaz de reduzir a liberdade dos indivíduos e trazer perdas até então não observadas para as atividades econômicas.

Palavras-chave: Medo do crime. Atividades de lazer. Economia do Crime. Probit bivariado recursivo.

\section{ABSTRACT THE IMPACTS OF FEAR OF CRIME ON THE LEISURE ACTIVITIES CONSUMPTION IN BRAZIL}

This study aims to assess how the fear of crime affects the consumption of individuals' leisure activities, such as going to cinemas, shopping malls, parks, sporting events, fairs, bars, restaurants and concerts. To this goal, this study uses data from the National Victimization Survey of 2012 to estimate a bivariate recursive Probit, a model capable of dealing with potential endogeneity problems. The results indicate that fear reduces the probability of leisure consumption in most of the investigated activities, with emphasis on sporting events, with a reduction 
estimated of 13,2\%, however, an increase was observed in the consumption of activities that offer more safety for clients, such as fairs and shopping malls, with increases estimated of $6 \%$ and 7,2\% respectively. The study concludes that crime implies on losses of well-being that go beyond the economic losses customarily accounted for in studies of crime costs, because it cannot be ignored that fear of crime is capable of reducing the individuals' freedom and of generating so far non-observed losses to economic activities.

Keywords: Fear of crime. Leisure activities. Economics of crime. Recursive bivariate Probit.

DOI: 10.31060/rbsp.2021.v15.n1.1179

Data de recebimento: 30/06/2019 - Data de aprovação: 22/06/2020

\section{INTRODUÇÃO}

É um fato que as altas taxas de criminalidade no Brasil geram uma sensação de insegurança e medo para a sua população. Infelizmente esse medo é fundamentado nos números alarmantes que o crime apresenta no Brasil. Dados do Anuário Brasileiro de Segurança Pública indicavam que em 2012, ano base deste estudo, cerca de 50 mil pessoas morreram vítimas de agressões violentas naquele ano no país, o equivalente a uma taxa de homicídios de 28 mortes a cada 100 mil habitantes. Números que colocavam o Brasil, de acordo com a Organização Mundial de Saúde, em 2012, entre os países com as mais altas taxas de homicídios do mundo, atrás apenas de países como Honduras (85,5), Guatemala (34) e Colômbia (34), e muito distante de países desenvolvidos como Estados Unidos $(5,3)$, Canadá $(1,36)$, Nova Zelândia $(0,9)$ e Noruega $(0,3)$. Esses altos índices de violência levam o Brasil a sofrer determinados impactos adversos que não são sentidos em países desenvolvidos.

Esse contexto adverso, além de criar uma demanda ímpar em relação ao resto do mundo pelo sistema de saúde, pela justiça criminal e por serviços sociais, gera uma necessidade de adaptação por parte de sua população, que passa a ter um comportamento autoprotetor que se reflete, entre outras coisas, em restrições ao convívio social e no consumo de atividades de lazer em locais e horários em que os indivíduos se sintam mais seguros (LISKA; SANCHIRICO; REED, 1988).

Segundo Garofalo (1981), o medo do crime é uma reação emocional caracterizada, na maioria das vezes, por uma percepção de perigo, gerado pela ameaça de dano físico. Entretanto, quando o medo é desencadeado por um palpite em relação ao que pode vir a acontecer, este significa uma antecipação do medo. Assim, o medo do crime é definido como os custos tangíveis e intangíveis da antecipação de uma possível vitimização por um crime (DOLAN; PEASGOOD, 2006). Como os indivíduos agem para evitar ou minimizar as situações estressantes, é comum esperar que o medo do crime possa gerar reações comportamentais que alterem as decisões de consumo tomadas pelos indivíduos. Por exemplo, Greenbaum e Tita (2004) mostram que escolhas importantes dos indivíduos, tais como o local onde moram, trabalham e fazem suas compras, estão sujeitas ao medo que esses indivíduos sentem do crime.

Cientes dessas preferências por segurança por parte de potenciais consumidores, empresários buscam formas de atrair mais clientes. Para Helms (2008) e Chatterton e Hollands (2002) os lugares mais seguros atraem mais consumidores e gastos. Logo, estabelecimentos que investem em equipamentos e estratégias de segurança, tais como circuitos de câmeras, estacionamentos fechados e com cancelas, seguranças armados e/ou vigias têm maior chance de receber mais consumidores, devido ao fato destes se sentirem mais tranquilos nesses locais, uma vez que não precisam se preocupar a todo instante com a possibilidade de serem vitimados por um crime. Em contrapartida, o consumo de bens e serviços que 
são oferecidos em locais considerados como inseguros pelos consumidores é afetado negativamente (BRANDS; VAN AALST; SCHWANEN, 2015).

Do ponto de vista teórico, essas mudanças no comportamento e nas escolhas feitas pelos consumidores são previstas pela teoria de prevenção (controle) situacional do crime1. Clarke $(1980,1995)$ destaca que a prevenção situacional do crime é a tomada de medidas que visam a manipulação de ambientes, a fim de reduzir as oportunidades para a prática de crimes e aumentar os riscos percebidos pelos potenciais criminosos. Essas medidas são amplas e diversificadas e vão desde instalação de vigilância eletrônica, separação dos times de futebol nas arquibancadas dos estádios, contratação de guardas, instalação de alarmes, entre outras medidas de prevenção que buscam prevenir crimes (CLARKE, 1995; LISKA; SANCHIRICO; REED, 1988).

Por sua vez, as abordagens de Cohen e Felson (1979) e de Cornish e Clarke (1985) relacionam as taxas de vitimização com a oportunidade da ação criminosa. Os autores sugerem que as atividades de rotina podem facilitar a ação de potenciais criminosos de forma que a alocação do tempo em atividades como ir ao local de trabalho ou de estudo, fazer compras e frequentar locais por lazer podem ajudar a explicar as diferentes probabilidades de vitimização às quais os indivíduos estão sujeitos. Além da oportunidade para o crime ocorrer, os autores sugerem que a ação criminal depende da motivação e da capacidade dos infratores para realizarem o crime, tal como propõe o modelo de Becker (1968), todavia, acrescentam a necessidade da existência de alvos adequados e da ausência de um guardião capaz de desencorajar o criminoso, sendo que a falta de qualquer um desses fatores pode ser suficiente para evitar que crimes ocorram.

Por exemplo, para Cornish e Clarke (1985) as crescentes taxas criminais nos Estados Unidos pós-década de 1960 estão relacionadas às mudanças de hábitos da população. Houve um crescimento no número de pessoas trabalhando e realizando atividades fora de casa, ao mesmo tempo, essas pessoas passaram a consumir uma quantidade maior de produtos valiosos e de fácil transporte capazes de atrair potenciais criminosos, tais como carros, eletrodomésticos, eletroeletrônicos e produtos. Assim, segundo os autores, essas mudanças alteraram a probabilidade de potenciais criminosos motivados convergirem no espaço e no tempo, com o aumento desses alvos adequados e sem guardiões capazes, resultando, assim, em aumentos nas taxas de criminalidade ao longo do tempo.

Nessa perspectiva, as taxas de criminalidade estariam relacionadas com o tempo em que as pessoas estão no trabalho, na escola ou em lazer e no benefício marginal percebido pelos criminosos (COHEN; FELSON, 1979). Porém, Clarke (1995) ressalta que um comportamento evasivo influencia negativamente as oportunidades criminais. Sendo assim, o medo do crime impõe custos adicionais às vítimas, uma vez que estas desenvolvem um comportamento protetor para evitar a vitimização, por exemplo, se privando de consumir determinados produtos ou se privando de sua liberdade para realizar certas atividades e frequentar determinados locais. Isso afeta diretamente os mercados e consequentemente a economia como um todo. Pois, por exemplo, um indivíduo pode deixar de consumir um produto de maior valor, tal como um telefone celular de última geração, simplesmente porque este é um atrativo para potenciais criminosos capaz de gerar uma antecipação (medo) de um possível crime no futuro. Assim, em um ambiente com altas taxas de criminalidade, vários consumidores optam por aparelhos de telefone mais simples e baratos, e isso altera a estrutura daquele mercado. O mesmo raciocínio é válido para o consumo de outros bens e serviços, tais como os fornecidos pelas atividades de lazer.

1 O modelo de prevenção situacional tem sua fundamentação baseada na abordagem da escolha sugerida por Cornish e Clarke (1985), na perspectiva econômica da Escolha Racional de Becker (1968) e na Teoria das Atividades Rotineiras desenvolvida por Cohen e Felson (1979). 
A literatura mostra que o consumo de atividades de lazer é influenciado tanto por restrições de tempo que os indivíduos possuem quanto por restrições financeiras (FEATHER; SHAW, 1999). De forma que o consumo dessas atividades gera um custo de oportunidade que pode ser medido em termos de rendimentos (salários) que deixam de ser recebidos. Os modelos econômicos de demanda por lazer se baseiam na suposição de que os indivíduos buscam ajustar a quantidade de horas dispendidas em lazer e trabalho de forma a maximizar a sua utilidade. No entanto, para muitos indivíduos a flexibilização de horas de trabalho não é possível, uma vez que devem cumprir jornadas de trabalho fixas. Mesmo assim, embora o tempo não possa ser armazenado diretamente, pode ser indiretamente transferido entre períodos, mediante a transferência de compromissos (PHANEUF; SMITH, 2005). Esse tempo "livre" pode ser alocado, entre outras possibilidades, no consumo de atividades de lazer (OWEN, 1971).

Entretanto, esses modelos de demanda por atividades de lazer ignoram que existem custos que vão além dos custos de oportunidade e os custos diretos dessas atividades, como, por exemplo, com o pagamento por ingressos e demais serviços nos locais em que essas atividades estão localizadas. O consumo dessas atividades implica em diferentes riscos, dentre os quais o de ser vítima de um crime. Do ponto de vista dos indivíduos, esses riscos são avaliados tanto em relação às suas probabilidades quanto em relação às suas consequências, que envolvem custos materiais e emocionais. De maneira que, quando há uma percepção de que esses riscos são muito altos, é possível que exista uma disposição a pagar para mitigálos (MOEN; RUNDMO, 2004) ou simplesmente uma indisposição em assumir esses riscos. Neste último caso, há um custo adicional imposto pelo comportamento autoprotetor por parte dos indivíduos, que perdem sua liberdade de escolha e se limitam a frequentar locais que proporcionem uma sensação maior de segurança, tal como prevê a teoria de prevenção situacional do crime.

Então, nesse contexto, este estudo levanta a hipótese de que o consumo de certas atividades de lazer no Brasil é afetado pelo medo que os brasileiros possuem de serem vítimas de algum tipo de crime. Apesar de se tratar de um problema relevante, existem poucos estudos empíricos que buscaram avaliar a relação entre o medo do crime e o consumo de bens e serviços.

Entre os poucos estudos empíricos que buscaram investigar o medo do crime e seu impacto no comportamento, cabe destacar os trabalhos de DeFronzo (1979), que tentou relacionar o medo do crime ao porte de armas, através do uso de modelos de equações simultâneas não recursivas. Os seus resultados indicam que o medo não tem influência significativa sobre o porte de arma, no entanto, o porte de arma reduz o medo do crime. Por sua vez, Becker e Rubinstein (2004) estudaram como o medo e a aversão ao risco afetavam a probabilidade de consumo de transporte público em situações de terrorismo. Nesse caso, segundo os autores, o medo se torna um fator depreciador do consumo. Os autores encontraram resultados que indicam uma redução de cerca de $20 \%$ na utilização de transporte público em ocasiões que ocorreram ataques suicidas com bomba. Assim, o medo associado a um ataque terrorista pode gerar efeitos consideráveis sobre o consumo de serviços de transporte.

Para o Brasil, ao que se sabe, não existem estudos que relacionam o medo do crime com o consumo de bens e serviços. Todavia, o medo do crime é estudado por Silva e Beato Filho (2013), que examinaram os fatores físicos e sociais de comunidades urbanas associados ao medo do crime e sua influência nas reações dos indivíduos. Para tanto, utilizaram os dados da Pesquisa de Vitimização realizada em 2006 e uma modelagem linear hierárquica para filtrar esses dados. Os autores evidenciaram, em seus resultados, que, quanto maior o tempo de moradia no local e quanto maior a interação social dos vizinhos, menor é o medo do crime, além disso, a percepção sobre o ambiente e as alterações de comportamentos dependem das relações sociais em nível de vizinhança. 
Dessa forma, é possível notar que na literatura existem poucos estudos que avaliam especificamente os impactos do medo do crime sobre as decisões de consumo e os custos para a sociedade em termos de perda de liberdade. Esses custos são ignorados por muitos estudos que se propõem a mensurar os custos do crime e que, no caso brasileiro, podem ter grandes proporções. Ademais, o medo do crime pode afetar diretamente as estatísticas de criminalidade, uma vez que muitos crimes deixam de ser cometidos simplesmente porque em determinados locais há uma restrição à liberdade de potenciais vítimas, o que reduz as oportunidades para que crimes ocorram.

Sendo assim, com o intuito de preencher essa lacuna empírica, este trabalho, ao que se sabe de forma inédita no Brasil, busca avaliar se o medo do crime afeta a probabilidade dos indivíduos consumirem determinadas atividades de lazer, tais como ir a cinemas, shoppings, parques, eventos esportivos, feiras, bares, shows e sair para comer. Para este fim, utiliza dados da Pesquisa Nacional de Vitimização (PNV) referente ao ano de 2012, uma amostra com aproximadamente 78 mil entrevistas cobrindo todo o território nacional, para estimar um modelo Probit bivariado recursivo. A escolha por este método visa reduzir os problemas de endogeneidade, por exemplo, causados pela existência de variáveis omitidas correlacionadas com as variáveis que foram incluídas no modelo. Com este propósito, este estudo foi estruturado em quatro seções, iniciando-se por esta introdução. A seção seguinte apresenta a base de dados utilizada e a metodologia adotada. Posteriormente, apresentam-se os resultados encontrados e a conclusão do trabalho.

\section{ESTRATÉGIA DE IDENTIFICAÇÃO}

O modelo econométrico proposto por este estudo tem o objetivo de analisar a escolha conflitante de um indivíduo ao decidir se frequenta ou não determinados lugares diante do medo de ser vitimado. De maneira que a probabilidade de um indivíduo frequentar um determinado local dependerá do medo que ele sente em realizar tal ação. Assim, é possível construir um modelo de escolhas binárias não linear em que há um fator endógeno entre elas. De acordo com Greene (2002), isso pode ser tratado com a utilização do modelo Probit bivariado recursivo, desenvolvido por Madalla e Lee (1976). O modelo parte de uma função utilidade individual, que pode ser representada pela seguinte equação:

$$
u^{i}=x_{i} \beta+z_{i} \alpha+\varepsilon_{i}
$$

$U^{i}$ é a utilidade do indivíduo i;

$\boldsymbol{x}_{\boldsymbol{i}}$ é um vetor de covariadas que afeta a probabilidade em frequentar os locais selecionados;

$z_{i}$ é a probabilidade de perda, em que perdas altas implicam em medo $=1$;

$\varepsilon_{i}$ é o resíduo.

O indivíduo í irá a um local se a sua utilidade em tal ação for maior do que a utilidade em não ir. Todavia, há um fator endógeno que relaciona as variáveis frequentar ou não frequentar e ter ou não ter medo, de forma que uma probabilidade (de frequentar/consumir ou não) está relacionada com a probabilidade (ter medo ou não) de ser vítima ou não. Levando isso em consideração, se busca encontrar uma variável latente $y^{*}$, que representa a diferença da utilidade em frequentar e da utilidade em não frequentar, dada por:

$$
y^{1}=x \beta+z \alpha+\varepsilon_{1}
$$


$y^{*}$ é a variável latente, ou seja, um componente não observável da variável dicotômica y, que indica a disposição a consumir do indivíduo; será positiva caso a utilidade em frequentar um local seja maior que a utilidade em não frequentar esse local, e negativa, caso contrário.

$$
\begin{aligned}
& y=1 \text { so } y^{\prime}>0 \\
& y=0 \text { sc } y^{\prime} \leq 0
\end{aligned}
$$

Entretanto, essa decisão depende do medo que o indivíduo tem ou não do crime, assim, a decisão de ter medo ou não pode ser representada pela função de utilidade dada pela equação 4, enquanto a diferença de utilidade entre ter medo ou não é representada pela equação 5.

$$
\begin{gathered}
z=w \alpha+\varepsilon \\
z^{\prime}=w \theta+\varepsilon_{z}
\end{gathered}
$$

Nesse caso, a variável $w$ representa um vetor de covariadas. A variável latente $\boldsymbol{z}$ ' será positiva se a utilidade em ter medo for maior que a utilidade em não ter medo, e vice-versa, então, observa-se que as variáveis dicotômicas assumem:

$$
\begin{aligned}
& z=1 \text { se } z^{1}>\bar{z} \\
& z=0 \text { se } z^{1} \leq \bar{z}
\end{aligned}
$$

Sendo assim, o modelo Probit bivariado recursivo de equações simultâneas é representado pelas equações 2 e 5 , de acordo com Maddala e Lee (1976). Assumindo que $\left(\varepsilon_{1}, \varepsilon_{2} \mid x_{1} w\right) \cdots N(0,0,1,1, p)$, em que $N$ é uma distribuição normal padrão bivariada com coeficiente de correlação igual a $\rho$, dada por:

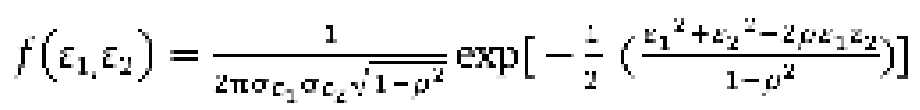

De acordo com Oliveira (2018), quatro relações podem ser estudadas a partir desse modelo: a correlação entre ye $z$, o efeito de ye $z$ sobre o parâmetro $\boldsymbol{\alpha}$, os efeitos das covariadas em ye $z$, e a correlação entre os componentes não observados do modelo, $\rho$. Neste estudo há uma busca por relações causais entre a variável de resultado (frequência/consumo de uma atividade de lazer) e as suas covariadas potencialmente endógenas (o medo do crime). Mais especificamente, os principais objetivos são:

a. Identificar se há uma relação do medo do crime sobre o consumo através do parâmetro $\boldsymbol{\alpha}$;

b. Verificar se há efeitos das covariadas observáveis e exógenas sobre o medo do crime e sobre o consumo, ou seja, se o medo e o consumo podem depender de $x$;

c. Avaliar se há correlação entre os componentes não observáveis do modelo, pois consumo e medo podem depender dessas variáveis.

Com relação ao último objetivo acima, cabe ressaltar que quando $\rho=0$ o modelo torna-se um Probit padrão e se tem somente uma probabilidade condicional (ARENDT; LARSEN, 2006). Caso contrário, são encontradas quatro distribuições de probabilidades condicionais (MADALLA; LEE, 1976, OLIVEIRA, 2018):

$$
P(y=1 / z=1), P(y=1 / z=0), P(y=0 / z=1), P(y=0 / z=0)
$$


Assumindo que $\varepsilon_{1} \varepsilon_{2}$ são simetricamente distribuídos, as funções podem ser maximizadas por máxima verossimilhança. Em relação aos efeitos marginais estimados, Oliveira (2018) ressalta que é importante analisar os efeitos das variáveis exógenas sobre a probabilidade de $y$, no caso do presente estudo, a probabilidade de frequentar atividades de lazer, além do efeito médio do tratamento, ou seja, o efeito médio de ter medo sobre a variável de interesse.

Para estimar o modelo proposto foram utilizadas informações extraídas da Pesquisa Nacional de Vitimização (PNV) referente ao ano de 2012, na qual foram entrevistadas aproximadamente 78 mil pessoas em todo o território nacional. Essa pesquisa foi contratada pelo Ministério da Justiça, por meio da Secretaria Nacional de Segurança Pública (Senasp), e realizada pelo Instituto de Pesquisas Datafolha e o Centro de Estudos de Criminalidade e Segurança Pública (Crisp). Sua primeira edição foi em 2006 e, desde então, traz informações acerca das condições de segurança da população urbana, contribuindo para mensurar as experiências de vitimização criminal, além disso, aborda aspectos sobre a epidemiologia e etiologia do crime, pois contém informações a respeito do perfil das vítimas, do grau de confiança nas instituições, do medo do crime e da violência e das mudanças de comportamento advindas desse fator social. Certamente esta pesquisa supre uma lacuna sobre informações a respeito da vitimização por crime no país, contribuindo para a pesquisa acadêmica e o desenvolvimento de políticas públicas focalizadas.

As variáveis utilizadas neste estudo estão listadas na Tabela 1. Como o interesse é saber se o medo do crime afeta a probabilidade de os indivíduos frequentarem determinados lugares, agindo assim de forma preventiva, foram utilizadas como variáveis dependentes as informações referentes ao consumo em atividades de lazer fornecidas pela pesquisa, a dizer, idas a cinema, praia ou parque, comer fora de casa, assistir aos eventos esportivos ao vivo, ir a shopping ou centro comercial, feiras, show ou espetáculo, bar e casa noturna. Essas variáveis assumem valor 1 caso o indivíduo responda que frequentou algum desses locais nos últimos trinta dias, e valor 0 , caso contrário. Por sua vez, o medo do crime é representado por três categorias disponíveis na pesquisa: i) o medo de ter a residência invadida; ii) o medo do crime contra o patrimônio, representado pelo medo de ter objetos pessoais de valor tomados à força; e iii) o medo de ser assassinado. Caso a pessoa tenha medo, a variável assume valor igual a 1 e valor 0, caso contrário.

Ademais, foram incluídas variáveis de controle de características pessoais, como sexo, idade, estado civil, cor, ocupação, renda e meio de transporte que costuma utilizar. Neste caso, a idade e a renda foram separadas em classes e transformadas em variáveis dummies, que assumem valor 1 se o indivíduo está na determinada classe e valor 0 , caso contrário. Por sua vez, a variável meio de transporte foi dividida em quatro categorias: carro, moto, ônibus e bicicleta/a pé.

\section{TABELA 1}

\begin{tabular}{l|l}
\hline Descrição das variáveis utilizadas & \\
\hline Variáveis dependentes & Descrição \\
\hline Saiu para ir ao cinema? & \\
Saiu para ir à praia ou ao parque? & \\
Saiu para comer fora de casa, sem contar os dias & 1 se sim, 0 caso contrário \\
de trabalho? & \\
Saiu para assistir a algum evento esportivo & \\
amador ou profissional ao vivo? & \\
Saiu para ir ao shopping ou ao centro comercial? & \\
Saiu para ir às feiras populares? & \\
Saiu para assistir a algum show ou espetáculo & \\
de música, dança? & \\
Saiu para ir a algum bar ou alguma casa & \\
noturna? &
\end{tabular}




\begin{tabular}{|c|c|}
\hline Variáveis independentes & Descrição \\
\hline 1- Medo de ter a residência invadida & 1 se tem medo, 0 caso contrário \\
\hline $\begin{array}{l}\text { 2- Medo de crime contra o patrimônio: medo de } \\
\text { ter objetos pessoais de valor tomados à força } \\
\text { por outras pessoas em um roubo ou assalto }\end{array}$ & 1 se tem medo, 0 caso contrário \\
\hline 3- Medo de morrer assassinado & 1 se tem medo, 0 caso contrário \\
\hline Sexo & 1 masculino, 0 caso contrário \\
\hline Classe de idade: & \\
\hline $1-16$ a 24 anos & \\
\hline $2-25$ a 34 anos & 1 se dentro da classe de idade, 0 caso contrário \\
\hline 3- 35 a 44 anos & \\
\hline 4- 45 a 59 anos & \\
\hline 5- 60 anos ou mais & \\
\hline Estado civil & 1 se casado, 0 caso contrário \\
\hline Cor & 1 se branco ou amarelo, 0 caso contrário \\
\hline Ocupação & 1 se faz parte da PEA, 0 caso contrário \\
\hline Renda domiciliar total (por faixas): & \\
\hline 1- Até 1 salário mínimo & 1 se recebe até 1 salário mínimo, 0 caso contrário \\
\hline 2- 1 a 2 salários mínimos & 1 se recebe entre 1 e 2 salários mínimos, 0 caso contrário \\
\hline 3- 2 a 3 salários mínimos & 1 se recebe entre 2 e 3 salários mínimos, 0 caso contrário \\
\hline 4- 3 a 5 salários mínimos & 1 se recebe entre 3 e 4 salários mínimos, 0 caso contrário \\
\hline 5- Acima de 5 salários mínimos & 1 se recebe acima de 5 salários mínimos, 0 caso contrário \\
\hline Meio de transporte: & \\
\hline Carro & 1 se utiliza carro, 0 caso contrário \\
\hline Moto & 1 se utiliza moto, 0 caso contrário \\
\hline Ônibus & 1 se utiliza ônibus, 0 caso contrário \\
\hline Bicicleta/a pé & 1 se utiliza bicicleta ou anda a pé, 0 caso contrário \\
\hline
\end{tabular}

Fonte: Elaboração própria.

Do total de entrevistados na pesquisa, 81,59\% responderam que tinham pelo menos um dos medos descritos na Tabela 2 e 53,73\% responderam ter os três tipos de medo. Esses percentuais estão muito acima dos de outros países do mundo. Por exemplo, Farrall e Gadd (2004) mostram que na década de noventa essa taxa era algo em torno de 25\% nos EUA, na Austrália e na Europa. Por sua vez, em 2002, em pesquisa sobre a frequência em que as pessoas sentiam medo, realizada no Reino Unido, se verificou que aproximadamente 39\% da população dizia já ter sentido medo mais do que cinco vezes, sendo que apenas 8\% dessas pessoas sentiram uma intensidade muito alta de medo do crime naquele mesmo ano. De qualquer forma, os números brasileiros destoam dos observados em pesquisas anteriores, não somente em percentuais, mas também com relação ao tipo de medo, pois não é observado em pesquisas análogas no resto do mundo que quase dois terços da amostra tenham medo de ser assassinados. Isto certamente é um reflexo das altas taxas de homicídios observadas no país.

\section{TABELA 2}

\begin{tabular}{lc}
\hline Percentual de indivíduos que declararam ter medo de crime, por tipo de medo (em \%) \\
\hline Tipo de medo & Percentual \\
\hline Residência invadida & 73,25 \\
\hline Objetos roubados & 70,49 \\
\hline Ser assassinado & 63,60 \\
\hline
\end{tabular}


Em relação às variáveis de interesse do estudo, a Tabela 3 mostra que as atividades de lazer mais frequentes são sair para comer, ir ao shopping e à feira, com percentuais entre $35 \%$ a $42 \%$, enquanto as atividades menos frequentes são ir a cinemas, shows e eventos esportivos, com percentuais entre $8 \%$ a $11 \%$. Ademais, por meio das estatísticas descritivas mostradas na Tabela 3 é possível observar que as atividades de lazer são mais comuns no cotidiano dos indivíduos que estão nas faixas mais altas de renda. Na medida que a renda cresce, aumenta a participação em todos os tipos de atividade. Ir ao cinema, sair para comer e ir ao shopping são atividades que ganham, no mínimo, quatro vezes mais consumidores quando se compara indivíduos que ganham até um salário mínimo com quem ganha mais de cinco salários mínimos. A única atividade que não mostra essas variações significativas por renda é a ida à feiras, os percentuais oscilam entre $32 \%$ e $38 \%$.

\section{TABELA 3}

\begin{tabular}{|c|c|c|c|c|c|c|c|c|}
\hline \multirow[b]{2}{*}{ Classe de renda } & \multicolumn{8}{|c|}{ Atividade } \\
\hline & Cinema & Parque & Comer & Ev. Esport. & Shopping & Feira & Show & Bar \\
\hline Até 1 salário mínimo & 2,15 & 10,83 & 17,14 & 5,75 & 25,98 & 32,70 & 6,77 & 9,92 \\
\hline 1 a 2 salários mínimos & 4,86 & 15,03 & 27,99 & 8,27 & 35,68 & 34,58 & 9,05 & 14,07 \\
\hline 2 a 3 salários mínimos & 8,41 & 20,51 & 41,69 & 11,03 & 45,69 & 35,64 & 11,60 & 18,67 \\
\hline 3 a 5 salários mínimos & 14,04 & 27,13 & 55,59 & 13,82 & 57,34 & 38,19 & 15,03 & 25,04 \\
\hline $\begin{array}{l}\text { Acima de } 5 \text { salários } \\
\text { mínimos }\end{array}$ & 20,82 & 33,63 & 63,76 & 15,52 & 62,39 & 37,81 & 18,47 & 31,06 \\
\hline Total & 8,77 & 19,83 & 37,90 & 10,19 & 42,86 & 35,39 & 11,38 & 18,32 \\
\hline
\end{tabular}

Fonte: Elaboração própria com base na PNV 2012 Nota: No ano de 2012, o salário mínimo correspondia a $R \$ 622,00$

A Tabela 4 apresenta as estatísticas descritivas para as covariadas utilizadas, que foram incluídas no modelo porque potencialmente exercem influência sobre as variáveis de frequência/consumo de lazer e de medo do crime. Há um consenso na literatura no qual características físicas e sociais como renda, raça, sexo e idade são relevantes ao determinar o medo do crime. Quanto maior a renda média, menor o medo que as pessoas sentem do crime, além disso, mulheres, negros e pessoas mais idosas são os grupos com mais medo, pois se sentem mais vulneráveis (FERRARO, 1995; GAROFALO, 1979; HALE, 1996; LISKA; SANCHIRICO; REED, 1988; ORTEGA; MYLES, 1987; SILVA; BEATO FILHO, 2013; WARR, 1984).

No que diz respeito ao lazer, as variáveis físicas e sociais também exercem influência, a literatura mostra que homens e mulheres têm preferências distintas de lazer e, geralmente, os primeiros têm mais horas disponíveis para essas atividades, principalmente nos fins de semana (SHAW, 1985). O meio de transporte é um determinante importante para a escolha da atividade de lazer, de acordo com Gronau e Kagermeier (2007), sendo que carros e transporte público são as opções mais procuradas para realizar esse tipo de atividade. Porém, cada evento faz o usuário reagir de uma forma quanto a que tipo de transporte utilizar (HE, 2012). Jara-Díaz e Farah (1987) acrescentam que a renda tem grande importância nas decisões de lazer, pois à medida que a renda aumenta, ampliam-se as opções de lazer. Havighurst e Feigenbaum (1959) abordam que pessoas da classe trabalhadora são centradas nas atividades de casa e pouco em atividades de lazer, enquanto pessoas das classes sociais mais altas possuem padrões de lazer ativos. 
TABELA 4

\begin{tabular}{|c|c|c|}
\hline \multicolumn{3}{|l|}{ Estatísticas descritivas das covariadas } \\
\hline Variável & Média & Desvio padrão \\
\hline Sexo & 0,4291 & 0,0018 \\
\hline Classe de idade 1 - 16 a 24 anos & 0,1674 & 0,0013 \\
\hline Classe de idade 2 - 25 a 34 anos & 0,2077 & 0,0014 \\
\hline Classe de idade 3 - 35 a 44 anos & 0,1837 & 0,0014 \\
\hline Classe de idade 4 - 45 a 59 anos & 0,2337 & 0,0015 \\
\hline Classe de idade 5 - 60 anos ou mais & 0,2075 & 0,0014 \\
\hline Casado & 0,4183 & 0,0018 \\
\hline Raça & 0,4754 & 0,0018 \\
\hline Carro & 0,4288 & 0,0018 \\
\hline Ônibus & 0,3010 & 0,0016 \\
\hline Moto & 0,1215 & 0,0012 \\
\hline Bicicleta/a pé & 0,0534 & 0,0008 \\
\hline PEA & 0,5236 & 0,0018 \\
\hline Classe de renda 1 - até 1 salário mínimo & 0,2098 & 0,0015 \\
\hline Classe de renda 2 - 1 a 2 salários mínimos & 0,2993 & 0,0016 \\
\hline Classe de renda 3 - 2 a 3 salários mínimos & 0,1872 & 0,0014 \\
\hline Classe de renda 4 - 3 a 5 salários mínimos & 0,1510 & 0,0013 \\
\hline Classe de renda 5 - acima de 5 salários mínimos & 0,1028 & 0,0011 \\
\hline
\end{tabular}

Fonte: Elaboração própria com base na PNV 2012. Notas: No ano de 2012, o salário mínimo correspondia a R\$ 622,00. Número de Observações: 78.560.

Ademais, o estado civil afeta as escolhas por lazer, pois casados geralmente preferem atividades familiares, enquanto solteiros se socializam mais com outras pessoas, frequentam mais bares e viajam mais (CRAWFORD; GODBEY, 1987; LEE; BHARGAVA, 2004; ORTHNER, 1975). Em suma, os fatores sociodemográficos como renda, status empregatício, idade, sexo e raça são potencialmente relevantes para determinar o uso do tempo para lazer (LEE; BHARGAVA, 2004). Tais relações serão avaliadas com maior propriedade após a estimação de modelos condicionais, que são apresentados na próxima seção.

\section{RESULTADOS}

Este estudo busca avaliar a hipótese de que indivíduos mudam seu comportamento diante do medo do crime, para tanto, foram estimadas 32 regressões que buscam identificar uma relação entre o medo do crime e a probabilidade das pessoas saírem de casa para consumir atividades de lazer, tais como ir a cinemas, praia ou parque, comer fora de casa, assistir aos eventos esportivos ao vivo, ir a shoppings ou centro comercial, feiras, shows ou espetáculos, bar e casa noturna.

Dadas as variáveis dependentes do modelo, entre as variáveis independentes estão as variáveis de medo, que foram divididas em quatro grupos: medo de ter a residência invadida, medo de ter objetos roubados, medo de ser assassinado e uma combinação com as pessoas que sentem os três tipos de medo simultaneamente. Além dessas, foram incluídas as variáveis de controle, como descritas na seção anterior.

Para verificar a endogeneidade das variáveis que representam o consumo de lazer com relação ao medo do crime, foram estimadas regressões pelo modelo e por Probit bivariado recursivo (PBR); os resultados 
são apresentados na Tabela A.1 do Apêndice A. As variáveis mostraram-se endógenas em grande parte dos modelos, indicando que a estimação por dois modelos Probit, separadamente, levariam a resultados inconsistentes. Sendo assim, o PBR, descrito na seção 3, foi utilizado para estimar 32 modelos. Além disso, todos os modelos utilizam erros padrões agrupados por Estados brasileiros, uma vez que se espera que cada Estado possua características próprias que podem apresentar heterogeneidade, tais como as suas políticas de segurança pública que, segundo a Constituição Federal, são de sua responsabilidade.

As estimações dos modelos de Probit bivariado recursivo permitem obter dois tipos de efeitos marginais distintos, o efeito médio do tratamento (EMT) e o efeito das variáveis exógenas. O EMT é obtido subtraindo a probabilidade condicional de consumir uma atividade de lazer dado que se tem medo de algum tipo de crime da probabilidade condicional de consumir uma atividade de lazer dado que não se tem medo de ser vítima de algum crime, com $z=1$ e $z=0$ fixo para cada observação. O efeito médio de tratamento é obtido calculando a média dessas diferenças nas probabilidades condicionais (OLIVEIRA, 2018). Os resultados do EMT são apresentados na Tabela 5 e representam a probabilidade de o evento ocorrer dadas as médias das covariadas.

Para facilitar as interpretações, os EMTs estimados são associados com as probabilidades de ocorrência dos eventos para calcular o percentual de redução no consumo de lazer em virtude do medo. Esses resultados são apresentados na Tabela 6. O medo de ter a residência invadida faz com que diminua o consumo de praticamente todas as atividades, a não ser as idas a feiras, shoppings e as saídas para comer. Oliveira (2018) mostra que a presença em casa reduz as chances de vitimização por crimes contra o patrimônio, de forma que os resultados mostram que um percentual razoável de indivíduos reduz o seu consumo de atividades de lazer porque consideram o local onde residem inseguro e/ou consideram ser necessário exercer a função de guardião da residência.

\section{TABELA 5}

\section{Efeito médio do tratamento por tipo de atividade de lazer}

\begin{tabular}{|c|c|c|c|c|}
\hline Tipo de medo & Cinema & Parque & Comer & Ev. Esport. \\
\hline 1- Ter a residência invadida & $\begin{array}{c}-0,0081^{* * *} \\
(0,0068)\end{array}$ & $\begin{array}{c}-0,0025^{* * *} \\
(0,0021)\end{array}$ & $\begin{array}{c}0,0216^{* * *} \\
(0,0065)\end{array}$ & $\begin{array}{c}-0,0005^{* * *} \\
(0,0078)\end{array}$ \\
\hline 2- Ter objetos roubados & $\begin{array}{c}0,0049 * * * \\
(0,0042)\end{array}$ & $\begin{array}{c}0,0029 * * * \\
(0,0013)\end{array}$ & $\begin{array}{c}0,0299 * * * \\
(0,0081)\end{array}$ & $\begin{array}{c}-0,0105^{* * *} \\
(0,0074)\end{array}$ \\
\hline 3- Ser assassinado & $\begin{array}{c}-0,0073 * * * \\
(0,0060)\end{array}$ & $\begin{array}{l}-0,0012 \\
(0,0063)\end{array}$ & $\begin{array}{c}0,0132 * * * \\
(0,0094)\end{array}$ & $\begin{array}{c}-0,0066 * * * \\
(0,0137)\end{array}$ \\
\hline $1+2+3$ & $\begin{array}{c}-0,0071 * * * \\
(0,0054)\end{array}$ & $\begin{array}{c}-0,0085 * * * \\
(0,0040)\end{array}$ & $\begin{array}{c}0,0114^{* * *} \\
(0,0068)\end{array}$ & $\begin{array}{c}-0,0134 * * * \\
(0,0134)\end{array}$ \\
\hline Tipo de medo & Shopping & Feira & Show & Bar \\
\hline 1- Ter a residência invadida & $\begin{array}{c}0,0446 * * * \\
(0,0135)\end{array}$ & $\begin{array}{c}0,0255^{* * *} \\
(0,0109)\end{array}$ & $\begin{array}{c}-0,0049 * * * \\
(0,0032)\end{array}$ & $\begin{array}{c}-0,0160 * * * \\
(0,0089)\end{array}$ \\
\hline 2- Ter objetos roubados & $\begin{array}{c}0,0589 * * * \\
(0,0094)\end{array}$ & $\begin{array}{c}0,0285 * * * \\
(0,0107)\end{array}$ & $\begin{array}{c}-0,0029 * * * \\
(0,0036)\end{array}$ & $\begin{array}{c}-0,0048^{* * *} \\
(0,0023)\end{array}$ \\
\hline 3- Ser assassinado & $\begin{array}{c}0,0297 * * * \\
(0,0061)\end{array}$ & $\begin{array}{c}0,0247 * * * \\
(0,0160)\end{array}$ & $\begin{array}{c}-0,0022^{* * *} \\
(0,0015)\end{array}$ & $\begin{array}{c}-0,0027 * * * \\
(0,0013)\end{array}$ \\
\hline $1+2+3$ & $\begin{array}{c}0,0310 * * * \\
(0,0116)\end{array}$ & $\begin{array}{c}0,0212 \\
(0,0138)\end{array}$ & $\begin{array}{c}-0,0045^{* * *} \\
(0,0025)\end{array}$ & $\begin{array}{c}-0,0114 * * * \\
(0,0055)\end{array}$ \\
\hline
\end{tabular}

Fonte: Elaboração própria com base na PNV 2012. Notas: Os valores representam o efeito do medo sobre a probabilidade condicional de praticar alguma das atividades relacionadas, são a diferença entre a probabilidade de um indivíduo que tem medo e de um indivíduo que não tem medo, dadas as covariadas. Os erros padrões obtidos por bootstrap são apresentados entre parênteses. * $p<0,10 ; * * 0<0,05 ; * * * p<0,01$. 
Os resultados mostram que o medo de ter objetos roubados reduz o consumo de eventos esportivos em cerca de 10\%, além de reduzir o consumo de shows e bares, em média, em 2,5\%. Por sua vez, o medo de ser assassinado tem impacto expressivo nas idas ao cinema, uma redução de 8,3\%, e nas idas aos eventos esportivos, uma redução de 6,5\%.

\section{TABELA 6}

Percentual de variação no consumo de atividades de lazer ocasionada pelo medo do crime, por tipo de medo (em \%)

\begin{tabular}{|l|c|c|c|c|c|c|c|c|}
\hline Classe de renda & Cinema & Parque & Comer & Ev. Esport. & Shopping & Feira & Show & Bar \\
\hline 1- Ter a residência invadida & $-9,2$ & $-2,3$ & 6,4 & $-12,0$ & 10,4 & 7,2 & $-4,3$ & $-8,7$ \\
\hline 2- Ter objetos roubados & 5,6 & 1,5 & 7,9 & $-10,3$ & 13,7 & 8,1 & $-2,5$ & $-2,6$ \\
\hline 3- Ser assassinado & $-8,3$ & $-0,6$ & 3,5 & $-6,5$ & 6,9 & 7,0 & $-1,9$ & $-1,5$ \\
\hline $1+2+3$ & $-8,1$ & $-4,3$ & 3,0 & $-13,2$ & 7,2 & 6,0 & $-4,0$ & $-6,2$ \\
\hline
\end{tabular}

Nota: As entradas foram obtidas através do cálculo do EMT, Tabela 5, sobre o percentual de indivíduos que frequentam cada atividade.

Uma combinação dos três tipos de medo tem resultados semelhantes, em termos de sinais, com os anteriores, sendo que o consumo de eventos esportivos é o mais impactado pelo medo do crime. As atividades relativas a eventos esportivos, shows e bares, em todos os casos, apresentaram redução no consumo devido ao medo. Esses locais, em geral, apresentam aglomerações de pessoas, além de serem atividades que ocorrem com maior frequência no período noturno, facilitando a ação de criminosos. Esses aspectos já foram discutidos pela literatura. Por exemplo, Brands Aalst e Schwanen (2015) destacam que uma economia noturna muito ativa deve tentar criar espaços seguros capazes de mitigar o medo, pois o contexto noturno é cercado por um discurso de vandalismo e desordem, fazendo com que o medo se intensifique nesses períodos; por outro lado, a introdução de um sistema de vigilância, policiamento e mais iluminação, segundo os autores, seriam capazes de reduzir esse sentimento.

Por sua vez, Almeida (2014) destaca que entre os motivos para não se frequentar estádios, locais públicos que promovem eventos esportivos, bares e restaurantes estão os custos para frequentar essas atividades de lazer e o medo da violência. Um local em que frequentemente ocorre eventos esportivos é o estádio de futebol e, neste contexto, Zani e Kirchler (1991) destacam que a violência é presente nesses locais e advém da competição e do fanatismo que acabam gerando, em algumas pessoas, um comportamento descontrolado e agressivo. Esse comportamento pode ser reforçado quando os indivíduos estão agindo de forma coletiva e sob efeito de álcool e drogas. Esse fato gera medo para os indivíduos que acabam se privando desse tipo de atividade. Logo, os resultados aqui observados estão em consonância com a literatura, pois se observa uma redução de 10,2\% na frequência a eventos esportivos pelo medo de sofrer um crime violento no deslocamento ou no próprio evento. Considerando o alto nível de violência observado no país e em eventos esportivos, não surpreende que os resultados deste estudo indiquem que há uma redução de 6,5\% na frequência em eventos esportivos devido ao medo de ser assassinado. Todavia, o efeito geral do medo sobre os eventos esportivos é de uma redução de 13,2\% de seu consumo. Isto certamente implica em uma perda considerável de faturamento para as atividades direta ou indiretamente ligadas a esses eventos.

Um resultado não esperado é a redução no consumo de cinema devido ao medo do crime, pois em cidades médias e grandes esses espaços geralmente se encontram dentro dos shoppings, que tiveram efeito oposto. É possível que variáveis que estão relacionadas ao consumo dessa atividade não estejam 
no modelo. Sá-Earp e Sroulevich (2009) comentam que a demanda por cinema apresenta altos custos, entre eles, a disponibilidade de tempo e dinheiro, o acesso e o gosto das pessoas, além disso, é grande a disponibilidade de ver filmes em casa a baixo custo, e esse conjunto de fatores faz com que se reduza o número de pessoas nas salas de cinema.

Em geral, os resultados indicam que é provável que os indivíduos substituam as atividades mais propensas ao risco por atividades mais seguras, tal como prevê a teoria da prevenção situacional do crime de Clarke $(1980,1995)$. Nesse caso, há uma perda de bem-estar devido à restrição que a violência impõe à liberdade, ou as pessoas deixam de ir aos locais ou buscam locais mais seguros, tais como os shoppings centers. Estes possuem circuitos de câmeras, seguranças, estacionamentos fechados etc. Os resultados mostram um aumento nas idas a esses locais de 7,2\% por causa do medo, sendo que o medo de ser roubado é o maior motivador para frequentar os shoppings.

Por sua vez, os efeitos marginais relacionados às covariadas utilizadas neste estudo são apresentados na Tabela 7 e evidenciam que a idade tem bastante influência na decisão do consumidor pelas atividades de lazer. Jovens de 16 a 24 anos têm maior probabilidade de consumir as atividades selecionadas, com exceção das feiras, isso quando comparados com indivíduos com mais de 60 anos. Ser casado aumenta a probabilidade de ir à feira e ao parque, ao mesmo tempo que reduz as probabilidades de frequentar os outros lugares. Pressupõe-se que a vida de casado faz com que as atividades desenvolvidas sejam em família, como idas ao shopping e saídas para comer.

A raça também se mostrou significativa em explicar as decisões de consumo das atividades de lazer, com exceção das idas às feiras. Ser branco ou amarelo reduz a probabilidade apenas de frequentar eventos esportivos, enquanto aumenta a chance de ir aos outros lugares. Ser do sexo masculino reduz a probabilidade de frequentar locais como cinemas, parques, sair para comer e ir ao shopping, e aumenta a probabilidade de ir a eventos esportivos, shows e bares. Esse resultado corrobora com o observado por Moreira (2006), que mostra que existem diferenças na demanda por entretenimento entre homens e mulheres para várias atividades. Segundo o autor, o homem possui maior atração por eventos esportivos, shows e bares, enquanto as mulheres preferem shoppings, cinemas e parques.

Em relação aos meios de transporte, cerca de $70 \%$ utilizam carro ou ônibus, variáveis que aumentam de forma estatisticamente significativa a probabilidade de frequentar os locais selecionados. O carro, em princípio, traz uma maior sensação de segurança, uma vez que o indivíduo não fica tão exposto às aglomerações e, de acordo com Cohen e Felson (1979), tanto o carro quanto os vários outros aparatos (armas elétricas, de caça, telefone, rodovias) são avanços tecnológicos projetados para fins legítimos, que são úteis para fins de proteção, mas que, ao mesmo tempo, podem ser utilizados para facilitar a prática de crimes. Esse raciocínio também se aplica ao ônibus, porém, é fato que as ocorrências de assaltos a ônibus são frequentes. Andar a pé só apresenta impactos estatisticamente significativos para reduzir a probabilidade de ir ao cinema e aumentar a probabilidade de ir ao bar.

Participar da população economicamente ativa é estatisticamente significativo em aumentar a probabilidade de frequentar quase todos os locais, com exceção das feiras. Ademais, em relação à renda, é possível observar nos resultados que aqueles que recebem até três salários mínimos têm probabilidade reduzida de consumir todos os tipos de lazer, enquanto os que recebem mais de cinco salários mínimos têm uma probabilidade maior e significativa para o consumo de todos os tipos de lazer, logo, há claramente uma relação positiva já esperada, uma vez que, são bens normais, tal como descrevem Jara-Díaz e Farah (1987). 
TABELA 7

\begin{tabular}{|c|c|c|c|c|c|c|c|c|c|}
\hline \multicolumn{10}{|c|}{ Efeitos marginais das demais covariadas } \\
\hline Variável & Cinema & Parque & Comer & Ev. Esport. & Shopping & Feira & Show & Bar & Média \\
\hline Classe de idade $1-16$ a 24 anos & $0,1735^{* * *}$ & $0,1968 * * *$ & $0,2516 * * *$ & $0,0928 * * *$ & $0,2079 * * *$ & $-0,0008$ & $0,1168^{\star \star \star}$ & $0,2340^{* \star *}$ & 0,1674 \\
\hline Classe de idade $2-25$ a 34 anos & $0,1140^{* * *}$ & $0,1846 * * *$ & $0,2295^{* * *}$ & $0,0524 * * *$ & $0,2017 * * *$ & 0,0551 & $0,0636^{* * *}$ & $0,1952^{* * *}$ & 0,2076 \\
\hline Classe de idade $3-35$ a 44 anos & $0,0872 * * *$ & $0,1427 * * *$ & $0,1525^{* * *}$ & $0,0381 * \star *$ & $0,1667 * * \star$ & 0,0634 & $0,0354 * \star *$ & $0,1378 * * *$ & 0,1837 \\
\hline Classe de idade $4-45$ a 59 anos & $0,0341^{* * *}$ & $0,0652^{* * *}$ & $0,0661^{* * *}$ & $0,0210 * * *$ & $0,0941 * * *$ & 0,0399 & $0,0227^{* * *}$ & $0,0828 * * *$ & 0,2337 \\
\hline Estado civil & $-0,0177 * \star *$ & $0,0026^{*}$ & $-0,021 * * *$ & $-0,0048^{*}$ & $-0,0108$ & 0,0176 & $-0,0204 * \star \star$ & $-0,0734 * * *$ & 0,4182 \\
\hline Raça & $0,0175^{* * *}$ & $0,0086^{* * *}$ & $0,0357^{* * *}$ & $-0,0023^{* * *}$ & $0,0217 * * *$ & $-0,0012$ & $0,0024 * * *$ & $0,0129 * * *$ & 0,4753 \\
\hline Sexo & $-0,0153^{* * *}$ & $-0,0027^{*}$ & $-0,0621^{*}$ & $0,0399 * * *$ & $-0,0901 *$ & $-0,0234$ & $0,0040^{* * *}$ & $0,0435^{\star * *}$ & 0,4289 \\
\hline Carro & $0,0489 * * *$ & $0,0963^{* * *}$ & $0,2024 * * *$ & $0,0343^{* * *}$ & $0,1501^{* * *}$ & $0,0549 * *$ & $0,0316^{* \star *}$ & $0,0758 * * *$ & 0,4287 \\
\hline Ônibus & $0,0307 * * *$ & $0,0450 * * *$ & $0,0601^{* * *}$ & $0,0142 * * *$ & $0,0628 * * *$ & 0,0193 & 0,0074 & $0,0195^{* * *}$ & 0,3010 \\
\hline Moto & $0,0166^{* * *}$ & $0,0454^{* * *}$ & $0,1090 * * *$ & $0,0401^{* * *}$ & $0,0812^{\star * *}$ & $0,0554 * * *$ & $0,0288^{* \star *}$ & $0,0649 * * *$ & 0,1215 \\
\hline Bicicleta/a pé & $-0,0192 * * *$ & $-0,0060$ & $-0,0250$ & 0,0250 & $-0,0295$ & 0,0085 & 0,0053 & $0,0135^{* * *}$ & 0,0534 \\
\hline PEA & $0,0041^{* * *}$ & $0,0085^{* * *}$ & $0,0239 * * *$ & $0,0183^{* * *}$ & $0,0007^{* * *}$ & 0,0118 & $0,0121^{\star * *}$ & $0,0581 * * *$ & 0,5234 \\
\hline $\begin{array}{l}\text { Classe de renda } 1 \text { - até } 1 \text { salário } \\
\text { mínimo }\end{array}$ & $-0,0463 * * *$ & $-0,0748 * * *$ & $-0,1422 * * *$ & $-0,0285^{* * *}$ & $-0,1153 * * *$ & $-0,0184$ & $-0,0325^{* * *}$ & $-0,0708^{* * *}$ & 0,2097 \\
\hline $\begin{array}{l}\text { Classe de renda } 2 \text { - } 1 \text { a } 2 \text { salários } \\
\text { mínimos }\end{array}$ & $-0,0339 * * *$ & $-0,0488^{* * *}$ & $-0,0736^{* * *}$ & $-0,0162 * * *$ & $-0,0353 * * *$ & 0,0183 & $-0,0259 * * *$ & $-0,0420 * * *$ & 0,2993 \\
\hline $\begin{array}{l}\text { Classe de renda } 3-2 \text { a } 3 \text { salários } \\
\text { mínimos }\end{array}$ & $-0,0179 * * *$ & $-0,0174$ *** & 0,0025 & $-0,0037 * * *$ & 0,0314 & 0,0379 & $-0,0166^{* * *}$ & $-0,0129 * * *$ & 0,1871 \\
\hline $\begin{array}{l}\text { Classe de renda } 4 \text { - } 3 \text { a } 5 \text { salários } \\
\text { mínimos }\end{array}$ & 0,0009 & 0,0142 & $0,0826 * \star *$ & 0,0070 & $0,1045^{\star \star \star}$ & $0,0589 * * *$ & $-0,0082$ & $0,0222 * * *$ & 0,1509 \\
\hline $\begin{array}{l}\text { Classe de renda } 5 \text { - acima de } 5 \\
\text { salários mínimos }\end{array}$ & $0,0421^{* * *}$ & $0,0730 * * *$ & $0,2101^{* * *}$ & $0,0241^{* \star *}$ & $0,1889 * * *$ & $0,0708^{* * *}$ & $0,0055^{\star \star *}$ & $0,0983 * * *$ & 0,1028 \\
\hline
\end{tabular}

Fonte: Elaboração própria com base na PNV 2012 Notas: Entradas são efeitos marginais na média obtidos pela soma dos efeitos marginais condicionais. Média de cada categoria informada na última coluna. ${ }^{*} p<0,10 ;{ }^{* *} p<0,05 ;{ }^{* * *} p<0,01$

\section{CONCLUSÕES}

Com o intuito de verificar se o medo do crime tem efeito em reduzir o consumo de atividades de lazer no Brasil, tais como ir ao cinema, frequentar praias ou parques, comer fora de casa, ir aos eventos esportivos, frequentar shoppings ou centros comerciais, feiras, show ou espetáculo, bares e casas noturnas, foram estimados 32 modelos econométricos. A partir dos resultados obtidos foi possível observar que o medo do crime apresenta efeito significativo em reduzir a probabilidade dos brasileiros frequentarem bares, shows e eventos esportivos em percentuais que chegam a $13 \%$. Isto representa uma perda significativa de receitas que, sem o conhecimento gerado por este estudo, eram ocultas até então. Ao mesmo tempo, os resultados mostram um aumento na probabilidade de frequência aos shoppings e centros comerciais que chegam a $7 \%$, o que pode ser um indicativo que investimentos em segurança podem trazer retorno na forma de novos clientes. Logo, os resultados obtidos neste estudo contribuem para que os organizadores de eventos esportivos e artísticos e os proprietários de bares e casas noturnas tenham informações que permitam uma avaliação de custo-benefício com relação à adoção de medidas de segurança, tais como sistemas de vigilância com o uso de circuito de câmeras, seguranças, estacionamentos fechados e com iluminação.

Por fim, considerando conjuntamente os resultados deste estudo, cabe lembrar das contribuições de Cohen e Felson (1979), que destacam que são três os fatores que influenciam na criminalidade: as atividades de rotina das pessoas, a maior adequação do alvo e a diminuição da presença de um guardião. As atividades 
diárias de trabalho, estudo, lazer e interação social fazem com que os indivíduos estejam mais expostos ao crime, assim como as mudanças que ocorrem no estilo de vida descritas em Hindelang, Gottfredson e Garofalo (1978). Os autores afirmam que as pessoas mais jovens são mais propensas a serem vítimas do que os idosos, porque passam mais tempo fora de casa, onde têm maior probabilidade de entrar em contato com um potencial criminoso motivado. Além disso, homens e indivíduos solteiros sofrem mais vitimização, porque são mais propensos a sair de suas casas e, assim, estão mais expostos aos agressores, enquanto mulheres e idosos têm menos probabilidade de sair à noite ou em geral. Aqueles que trabalham ou frequentam a escola, apesar de estarem fora de casa, têm maior probabilidade de passar um tempo em ambientes seguros, logo, possuem menor probabilidade de serem expostos aos potenciais criminosos.

De forma que os indivíduos adaptam o seu estilo de vida e suas atividades rotineiras para evitar a vitimização, tal como prevê a teoria de prevenção situacional do crime de Clarke (1980). Todavia, existem atividades que não podem deixar de ser realizadas, tais como se deslocar para o trabalho e para a escola, e frequentar esses locais. Assim, os indivíduos reduzem sua exposição em atividades consideradas "menos" essenciais, tais como as atividades de lazer, resultando em uma perda significativa de bem-estar. Os resultados aqui observados corroboram com essas ideias ao mostrar que o medo do crime é capaz de alterar significativamente as decisões de consumo de atividades de lazer. Desta forma, fica evidenciado neste estudo que a violência pode trazer perdas ainda não mensuradas para os brasileiros, uma vez que, além da perda da liberdade por parte dos indivíduos, das perdas de ter de lidar com um ambiente de negócios ruim para empresas, altamente burocratizado e tributado, tanto os indivíduos quanto as empresas ainda têm de arcar com dispêndios em segurança para complementar o serviço de segurança provido pelo Estado, que se mostra insuficiente para garantir a segurança nos ambientes de lazer.

\section{REFERÊNCIAS}

ALMEIDA, E. B. O consumo público de eventos esportivos: um olhar para além dos estádios de futebol. São Paulo: FGV, 2014. Disponível em: <http://bibliotecadigital.fgv.br/dspace/handle/10438/11470?localeattribute=es>. Acesso em: 2 abr. 2018.

ARENDT, J. N.; LARSEN, H. A. Probit models with dummy endogenous regressors. SSRN Electronic Journal, 2006. Disponível em: <https://papers.ssrn.com/sol3/papers.cfm?abstract_id=994189>. Acesso em: 11 abr. 2018.

BECKER, G. S.; RUBINSTEIN, Y. Fear and the Response to Terrorism: An Economic Analysis. Chicago: Centre for Economic Performance, LSE, 2004.

Crime and punishment: An Economic Approach. Journal of Political Economy, v. 76, n. 2, p. 169$217,1968$.

BRANDS, J.; VAN AALST, I.; SCHWANEN, T. Safety, surveillance and policing in the night-time economy: (Re)turning to numbers. Geoforum, v. 62, p. 24-37, 2015.

Fear of crime and affective ambiguities in the night-time economy. Urban Studies, v. 52, p. 439$455,2013$.

CARDOSO, M. L. F.; LOUREIRO, P. R. A. Desempenho econômico de atividades comerciais noturnas e criminalidade. Brasília: UNB, 2017. Disponível em: <http://bdm.unb.br/handle/10483/18150>. Acesso em: 11 abr. 2018. 
CHATTERTON, P.; HOLLANDS, R. Theorizing urban playscapes: producing, regulating and consuming youthful nightlife city spaces. Urban Studies, v. 39, p. 95-116, 2002.

CLARKE, R. V. Situational Crime Prevention. Crime Justice, v. 19, p. 91-150, 1995. Disponível em: < https:// doi.org/10.1086/449230>. Acesso em: 11 abr. 2018.

Situational Crime Prevention: Theory and Practice. The British Journal of Criminology, v. 20, n. 2, p. 136-147, 1980.

COHEN, L. E.; FELSON, M. Social Change and Crime Rate Trends: A Routine Activity Approach. American Sociological Review, v. 44, p. 588-608, 1979.

CORNISH, D. B.; CLARKE, R. V. Modeling Offenders' Decisions: A Framework for Research and Policy. Crime and Justice, v. 6, p. 147-185, 1985.

CRAWFORD, D.; GODBEY, G. Reconceptualizing barriers to family leisure. Leisure Sciences, v. 9, p. 119127, 1987.

DEFRONZO, J. Fear of crime and handgun ownership. Criminology, v. 17, n. 3, p. 331-340, 1979.

DOLAN, P.; PEASGOOD, T. Estimating the economic and social costs of the fear of crime. British Journal of Criminology, v. 47, n. 1, p. 121-132, 2006.

FARRALL, S.; GADD, D. The Frequency of the Fear of Crime. British Journal of Criminology, v. 44, n. 1, p. 127-132, 2004.

FEATHER, P.; SHAW, W. D. Estimating the Cost of Leisure Time for Recreation Demand Models. Journal of Environmental Economics and Management, v. 38, n. 1, p. 49-65, 1999.

FERRARO, K. F. Fear of crime: Interpreting victimization risk. SUNY press, 1995.

GAROFALO, J. The fear of crime: Causes and consequences. The Journal of Criminal Law and Criminology, v. 72, n. 2, p. 839-857, 1981.

. Victimization and fear of crime. Journal of Research in Crime and Delinquency, n. 16, p. 80-97, 1979.

GREENBAUM, R. T.; TITA, G. E. The Impact of Violence Surges on Neighborhood Business Activity. Urban Studies, v. 41, n. 13, p. 2495-2514, 2004.

GREENE, W. H. Econometric Analysis. 7. ed. New Jersey: Prentice Hall, 2002.

GRONAU, W.; KAGERMEIER, A. Key factors for successful leisure and tourism public transport provision. Journal of Transport Geography, v. 15, n. 2, p. 127-135, 2007.

HALE, C. Fear of Crime: A Review of the Literature. International Review of Victimology, v. 4, n. 2, p. 79-150. 1996.

HAVIGHURST, R. J.; FEIGENBAUM, K. Leisure and Life-Style. American Journal of Sociology, v. 64, n. 4, p. 396-404, 1959.

$\mathrm{HE}, \mathrm{K}$. A behavior study of transport impacts of mega events. University of Southampton, Faculty of Engineering and the Environment, 2012.

HELMS, G. Towards Safe City Centres? Remaking the Spaces of an Old Industrial City. University of Glasgow, 2008. Disponível em: <http://theses.gla.ac.uk/id/eprint/2484>. Acesso em: 11 abr. 2018.

HINDELANG, M. J.; GOTTFREDSON, M. R.; GAROFALO, J. Victims of personal crime: an empirical foundation for a theory of personal victimization. Cambridge, Mass.: Ballinger Pub. Co., 1978. 
JARA-DÍAZ, S. R.; FARAH, M. Transport demand and user's benefits with fixed income: the goods/leisure trade - off revisited. Transportation Research, v. 21, p. 165-170, 1987.

LEE, Y. G.; BHARGAVA, V. Leisure Time: Do Married and Single Individuals Spend It Differently? Family and Consumer Sciences Research Journal, v. 32, p. 254-274, 2004.

LISKA, A. E.; SANCHIRICO, A.; REED, M. D. Fear of crime and constrained behavior specifying and estimating a reciprocal effects model. Social Forces, v. 66, n. 3, p. 827-837, 1988.

MADDALA, G. S.; LEE, L. F. Recursive Models with Qualitative Endogenous Variables. Annals of Economic and Social Measurement, v. 5, n. 4, p. 525-545, 1976.

MOEN, B. E.; RUNDMO, T. Explaining Demand for Risk Mitigation, Trondheim: Rotunde Publikasjoner, $n$. 86, 2004.

MOREIRA, F. A. Demanda e oferta de entretenimento: um estudo do segmento de Baixa Renda do distrito de Itaquera na Cidade de São Paulo. São Paulo: FGV, 2006. Disponível em: <https://bibliotecadigital.fgv.br/ dspace/handle/10438/5767>. Acesso em: 11 abr. 2018.

OLIVEIRA, C. The impact of private precautions on home burglary and robbery in Brazil. Journal of Quantitative Criminology, v. 34, n. 1, p. 111-137, 2018.

ORTEGA, S.T.; MYLES, J.L. Race and gender effects on fear of crime: an interactive model with age. Criminology, v.25, p.133-152, 1987.

ORTHNER, D. K. Leisure Activity Patterns and Marital Satisfaction over the Marital Career. Journal of Marriage and Family, v. 37, n. 1, p. 91-102, 1975.

OWEN, J. D. The Demand for Leisure. Journal of Political Economy, v. 79, n. 1, p. 56-76, 1971.

PAIN, R. Place, social relations and the fear of crime: a review. Progress in Human Geography, v. 24, n. 3, p. 365-387, 2000.

PHANEUF, D. J.; SMITH, V. K. Recreation Demand Models. Handbook of Environmental Economics, 1. ed., cap. 15, v. 2, p. 671-761, 2005.

SÁ-EARP, F.; SROULEVICH, H. O comportamento do consumidor de produtos culturais e os combos de entretenimento. In: MELO, V. A. (Org.). Lazer: aspectos históricos, configurações contemporâneas. São Paulo: Alínea, 2009.

O espectador eventual: notas sobre a demanda por cinema no Brasil. Políticas Culturais em Revista, v. 2, n. 1, p. 77-87, 2009. Disponível em: <https://portalseer.ufba.br/index.php/pculturais/article/ view/3738>. Acesso em: 11 abr. 2018.

SHAW, S. M. Gender and Leisure: Inequality in the Distribution of Leisure Time. Journal of Leisure Research, v. 17, p. 266-282, 1985.

SILVA, B. F. A.; BEATO FILHO, C. Ecologia social do medo: avaliando a associação entre contexto de bairro e medo de crime. Revista Brasileira de Estudos de População, v. 30, p. S155-S170, 2013.

WARR, M. Fear of victimization: Why are women and the elderly more afraid?. Social Science Quarterly, v. 65, p. 681-702, 1984.

ZANI, B.; KIRCHLER, E. When violence overshadows the spirit of sporting competition: Italian football fans and their clubs. Journal of Community. Appl. Soc. Psychol., v. 1, p. 5-21, 1991. 


\section{APÊNDICE A}

TABELA A. 1

\section{Resultados das estimações por Probit e Probit Bivariado Recursivo}

\begin{tabular}{|c|c|c|c|c|c|c|c|c|}
\hline \multirow[b]{2}{*}{ Variável medo } & \multicolumn{4}{|c|}{ Cinema } & \multicolumn{4}{|c|}{ Parque } \\
\hline & Probit & PBR & rho & $L^{2}$ & Probit & PBR & rho & $L^{2}$ \\
\hline 1- Ter a residência invadida & $\begin{array}{c}-0,062^{* * *} \\
(0,018)\end{array}$ & $\begin{array}{l}-0,221 \\
(0,389)\end{array}$ & $\begin{array}{l}0,0939 \\
(0,231)\end{array}$ & 0,15 & $\begin{array}{l}-0,018 \\
(0,016)\end{array}$ & $\begin{array}{c}0,059 \\
(0,322)\end{array}$ & $\begin{array}{l}-0,0457 \\
(0,191)\end{array}$ & 0,06 \\
\hline 2- Ter objetos roubados & $\begin{array}{c}0,036 \\
(0,022)\end{array}$ & $\begin{array}{l}-0,270 \\
(0,194)\end{array}$ & $\begin{array}{l}0,1802 \\
(0,109)\end{array}$ & $2,59 *$ & $\begin{array}{c}0,012 \\
(0,018)\end{array}$ & $\begin{array}{l}-0,013 \\
(0,238)\end{array}$ & $\begin{array}{l}0,0144 \\
(0,147)\end{array}$ & 0,010 \\
\hline 3-Ser assassinado & $\begin{array}{c}-0,056^{* * *} \\
(0,017)\end{array}$ & $\begin{array}{l}-0,149 \\
(0,228)\end{array}$ & $\begin{array}{l}0,0573 \\
(0,134)\end{array}$ & 0,18 & $\begin{array}{l}-0,008 \\
(0,002)\end{array}$ & $\begin{array}{l}-0,522^{*} \\
(0,326)\end{array}$ & $\begin{array}{c}0,3096 \\
(0,1962)\end{array}$ & 2,17 \\
\hline $1+2+3$ & $\begin{array}{c}-0,054^{* * *} \\
(0,016)\end{array}$ & $\begin{array}{c}0,576^{* * *} \\
(0,216)\end{array}$ & $\begin{array}{r}-0,3900 \\
(0,216)\end{array}$ & $6,66^{* * *}$ & $\begin{array}{l}-0,035 \\
(0,016)\end{array}$ & $\begin{array}{l}-0,350 \\
(0,702)\end{array}$ & $\begin{array}{l}0,1951 \\
(0,437)\end{array}$ & 0,19 \\
\hline & \multicolumn{4}{|c|}{ Comer } & \multicolumn{4}{|c|}{ Ev. Esport. } \\
\hline Variável medo & Probit & PBR & rho & $L^{2}$ & Probit & PBR & rho & $L^{2}$ \\
\hline 1- Ter a residência invadida & $\begin{array}{c}0,078^{* * *} \\
(0,019)\end{array}$ & $\begin{array}{c}0,094 \\
(0,327)\end{array}$ & $\begin{array}{r}-0,0095 \\
(0,196)\end{array}$ & 0,002 & $\begin{array}{c}-0,068^{* * *} \\
(0,015)\end{array}$ & $\begin{array}{c}0,536^{* * *} \\
(0,075)\end{array}$ & $\begin{array}{r}-0,3684 \\
(0,075)\end{array}$ & $51,14^{* * *}$ \\
\hline 2-Ter objetos roubados & $\begin{array}{c}0,098 * * * \\
(0,021)\end{array}$ & $\begin{array}{l}0,343^{*} \\
(0,202)\end{array}$ & $\begin{array}{c}-0,1476 \\
(0,123)\end{array}$ & 1,39 & $\begin{array}{c}-0,059 * * * \\
(0,015)\end{array}$ & $\begin{array}{c}0,619 * * * \\
(0,085)\end{array}$ & $\begin{array}{c}-0,4170 \\
(0,053)\end{array}$ & 47,03 *** \\
\hline 3-Ser assassinado & $\begin{array}{c}0,046^{\star * *} \\
(0,018)\end{array}$ & $\begin{array}{c}0,859^{* * *} \\
(0289)\end{array}$ & $\begin{array}{r}-0,5061 \\
(0,182)\end{array}$ & $5,18 * *$ & $\begin{array}{c}-0,041^{* *} \\
(0,019)\end{array}$ & $\begin{array}{c}-1,019 * * * \\
(0,163)\end{array}$ & $\begin{array}{l}0,5693 \\
(0,083)\end{array}$ & $27,75^{* * *}$ \\
\hline $1+2+3$ & $\begin{array}{l}0,037 * * \\
(0,017)\end{array}$ & $\begin{array}{c}0,888^{* * *} \\
(0,253)\end{array}$ & $\begin{array}{c}-0,5357 \\
(0,161)\end{array}$ & $7,01^{* * *}$ & $\begin{array}{c}-0,076^{* * *} \\
(0,019)\end{array}$ & $\begin{array}{c}-1,104 * * * \\
(0,136)\end{array}$ & $\begin{array}{c}0,624 \\
(0,073)\end{array}$ & $37,35^{* * *}$ \\
\hline & \multicolumn{4}{|c|}{ Shopping } & \multicolumn{4}{|c|}{ Feira } \\
\hline Variável medo & Probit & PBR & rho & $L^{2}$ & Probit & PBR & rho & $L^{2}$ \\
\hline 1- Ter a residência invadida & $\begin{array}{c}0,124 * * * \\
(0,015)\end{array}$ & $\begin{array}{c}-0,645^{\star *} \\
(0,338)\end{array}$ & $\begin{array}{l}0,4516 \\
(0,196)\end{array}$ & $3,90 * *$ & $\begin{array}{c}0,068 * * * \\
(0,017)\end{array}$ & $\begin{array}{c}-0,634^{* *} \\
(0,297)\end{array}$ & $\begin{array}{l}0,4118 \\
(0,174)\end{array}$ & $4,38 * *$ \\
\hline 2- Ter objetos roubados & $\begin{array}{c}0,171^{* * *} \\
(0,171)\end{array}$ & $\begin{array}{l}0,269 \\
(0,431)\end{array}$ & $\begin{array}{l}-0,0595 \\
(0,2592)\end{array}$ & 0,05 & $\begin{array}{c}0,077^{* * *} \\
(0,016)\end{array}$ & $\begin{array}{l}-0,663 \\
(2,299)\end{array}$ & $\begin{array}{l}0,4396 \\
(1,361)\end{array}$ & 0,08 \\
\hline 3-Ser assassinado & $\begin{array}{c}0,087^{* * *} \\
(0,016)\end{array}$ & $\begin{array}{c}0,454 \\
(2,256)\end{array}$ & $\begin{array}{r}-0,2253 \\
(1,393)\end{array}$ & 0,02 & $\begin{array}{c}0,065^{* * *} \\
(0,024)\end{array}$ & $\begin{array}{c}-0,953^{* *} \\
(0,385)\end{array}$ & $\begin{array}{l}0,6209 \\
(0,243)\end{array}$ & $3,38^{*}$ \\
\hline $1+2+3$ & $\begin{array}{c}0,089 * * * \\
(0,017)\end{array}$ & $\begin{array}{c}-1,068 * * * \\
(0,091)\end{array}$ & $\begin{array}{l}0,7249 \\
(0,125)\end{array}$ & $54,22^{* * *}$ & $\begin{array}{c}0,059 * * * \\
(0,021)\end{array}$ & $\begin{array}{c}-1,216^{* * *} \\
(0,142)\end{array}$ & $\begin{array}{l}0,8149 \\
(0,109)\end{array}$ & $12,39 * * *$ \\
\hline & \multicolumn{4}{|c|}{ Show } & \multicolumn{4}{|c|}{ Bar } \\
\hline Variável medo & Probit & PBR & rho & $L^{2}$ & Probit & PBR & rho & $L^{2}$ \\
\hline 1- Ter a residência invadida & $\begin{array}{l}-0,027^{*} \\
(0,015)\end{array}$ & $\begin{array}{l}0,182 \\
(0,215)\end{array}$ & $\begin{array}{l}-0,1251 \\
(0,130)\end{array}$ & 0,90 & $\begin{array}{c}-0,072 * * * \\
(0,012)\end{array}$ & $\begin{array}{c}-0,392^{* *} \\
(0,204)\end{array}$ & $\begin{array}{l}0,1881 \\
(0,118)\end{array}$ & 2,43 \\
\hline 2-Ter objetos roubados & $\begin{array}{l}-0,014 \\
(0,019)\end{array}$ & $\begin{array}{c}0,381^{* * *} \\
(0,129)\end{array}$ & $\begin{array}{l}-0,241 \\
(0,129)\end{array}$ & $8,42 * * *$ & $\begin{array}{l}-0,021 \\
(0,014)\end{array}$ & $\begin{array}{l}-0,092 \\
(0,395)\end{array}$ & $\begin{array}{l}0,0419 \\
(0,236)\end{array}$ & 0,03 \\
\hline 3-Ser assassinado & $\begin{array}{l}-0,013 \\
(0,019\end{array}$ & $\begin{array}{l}-0,156 \\
(0,250)\end{array}$ & $\begin{array}{c}0,086 \\
(0,144)\end{array}$ & 0,35 & $\begin{array}{l}-0,012 \\
(0,010)\end{array}$ & $\begin{array}{c}0,008 \\
(0,294)\end{array}$ & $\begin{array}{l}-0,012 \\
(0,178)\end{array}$ & 0,01 \\
\hline $1+2+3$ & $\begin{array}{l}-0,026 \\
(0,018)\end{array}$ & $\begin{array}{l}-0,155 \\
(0,149)\end{array}$ & $\begin{array}{c}0,079 \\
(0,091)\end{array}$ & 0,76 & $\begin{array}{c}-0,050 * * * \\
(0,008)\end{array}$ & $\begin{array}{c}0,001 \\
(0,327)\end{array}$ & $\begin{array}{l}-0,032 \\
(0,205)\end{array}$ & 0,02 \\
\hline
\end{tabular}

Fonte: Elaboração própria a partir de dados da PNV 2012. Notas: Os valores representam os coeficientes das estimações por Probit e Probit Bivariado Recursivo, sendo que o erro padrão está entre parênteses. Como variáveis dependentes têm-se oito tipos de lazer, descritos no topo de cada coluna. As variáveis relacionadas ao tipo de medo foram elencadas em quatro grupos, descritos na primeira coluna. ${ }^{*} p<0,10 ;{ }^{* *} p<0,05 ;{ }^{* * *} p<0,01$. 